\title{
The Iowa Polio Stories Oral History Project
}

\author{
KATHLEEN M. SCOTT
}

BY THE MID-1960s Jonas Salk's killed vaccine and Albert Sabin's live oral vaccine had largely eliminated the threat of polio in the United States. ${ }^{1}$ Prior to that time it was feared as a crippling and often deadly disease. As memories of the terror of polio fade, it is important to record the history of the experience. In the 1990s scholars began to focus their attention on polio as a subject of serious historical and cultural inquiry. In her 1992 analysis, Dirt and Disease: Polio Before FDR, Naomi Rogers employed the concepts of dirt and disease, poverty and infection, to focus on the epidemiology of polio and the curious fact that middle- and upper-class Americans appeared to suffer higher rates of affliction than immigrants. "By 1900," Rogers noted, "while most poor immigrant children had become infected and immune at an early age, children from clean, middle-class homes were at greater risk of the paralytic form of the disease." Jane S. Smith argued in her 1995 study, Patenting the Sun, that the polio vaccine raised popular expectations and possibly false hopes for a high-tech breakthrough for acquired immune deficiency syndrome (AIDS). And in his 2005 Pulitzer Prize-winning analysis, Polio: An American Story, David Oshinsky examined the reality of polio as a fairly uncommon disease. He also investigated America's obsession with polio and how it was portrayed in the media and popular culture. ${ }^{2}$ Despite the emergence

1. "Polio Conquest in Sight," The Science News-Letter 81 (4/14/1962), 229.

2. Jane S. Smith, Patenting the Sun: Polio and the Salk Vaccine (New York, 1990); Naomi Rogers, Dirt and Disease: Polio Before FDR (New Brunswick, NJ, 1992), THE ANNALS OF IOWA 67 (Spring-Summer 2008). (C) The State Historical Society of Iowa, 2008. 
of this national literature on polio, little has been published about polio in Iowa specifically, even though polio afflicted Iowans in unusually high proportions.

Beginning in 1910, polio epidemics recurred in Iowa every few years, peaking with 3,564 cases reported in Iowa in 1952. In 1994 Palimpsest editor Ginalie Swaim organized a photographic essay titled "An Iowa Polio Portfolio, 1939 to 1959." 3 The essay noted the importance of providing a human dimension to the epidemics. The Des Moines Register and Tribune photographs from 1939 to 1959 that are featured in Swaim's essay convey the complex duality of fear and hope in the expressions of a generation of Iowans with little or no medical explanation or cure for their condition. What remained absent from the historical record were the subjects' experiences in their own words. How did polio affect their lives, families, employment, physical health, and emotional spirit?

In 2006 the Iowa Center for the Book selected a popular account of the development of the polio vaccine, Jeffrey Kluger's Splendid Solution as its All Iowa Reads selection for 2007.4 In response to the intense conversation the book sparked, the All Iowa Reads Committee sought the participation of public libraries and volunteers across the state to encourage Iowans to share their stories about polio through its Web site and in a more proactive oral history project. The purpose of this brief essay is to call attention to that project as a valuable resource for Iowans, particularly for Iowa historians. The passing of two of the participants in the oral history project-Betty Stanfield and Jeri Fegan-since their interviews were recorded underscores the importance and urgency of chronicling their stories.

THE IOWA POLIO STORIES Oral History Project, funded by the Roy J. Carver Charitable Trust and the State Library of

quotation from p. 2; idem, "Race and the Politics of Polio: Warm Springs, Tuskegee, and the March of Dimes," American Journal of Public Health 97 (May 2007), 784-95; Tony Gould, A Summer Plague: Polio and Its Survivors (New Haven, CT, 1995); David Oshinsky, Polio: An American Story (New York, 2005).

3. “An Iowa Polio Portfolio, 1939 to 1959," Palimpsest 75 (1994), 4-13.

4. Jeffrey Kluger, Splendid Solution: Jonas Salk and the Conquest of Polio (New York, 2004). 


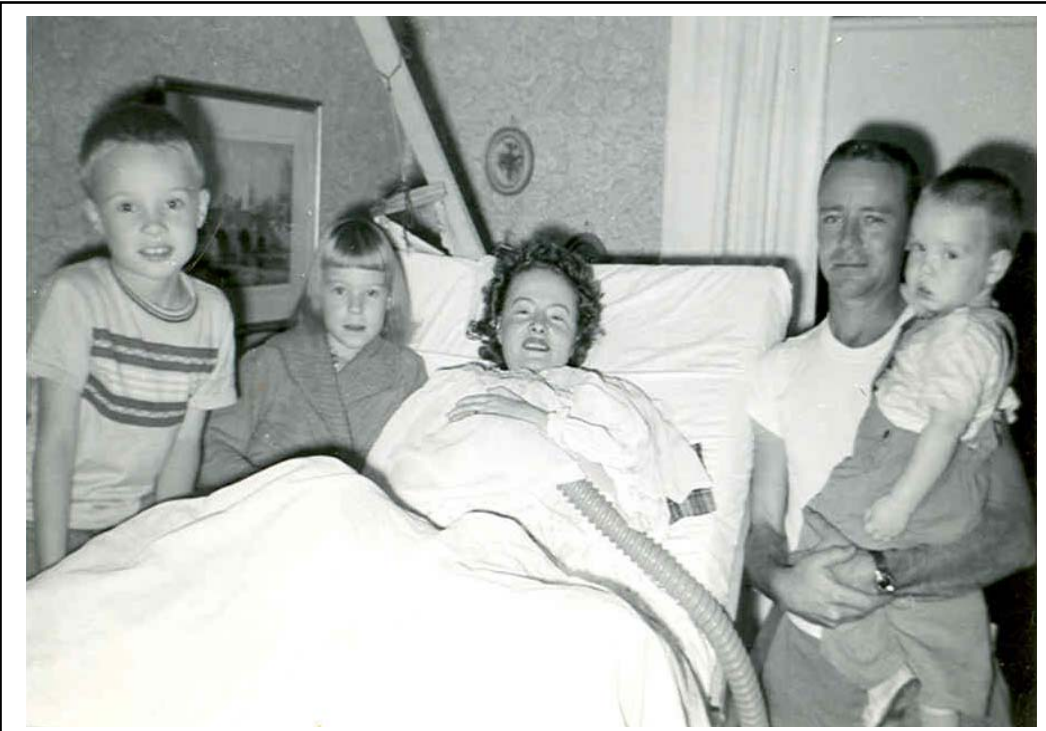

Beth Brown (1921-1971) is surrounded by her family, including husband Evan and interviewee Ann Brown LeMaster (pictured left of her mother), November 1956. Beth contracted polio in the fall of 1954. She was treated at Methodist and Lutheran Hospitals in Des Moines and later went to Omaha's Creighton Memorial-St. Joseph's Hospital for rehabilitation. For the rest of her life, Beth lived at home with the care of her own mother, her children, and hired help, in a paralyzed state from the neck down. Beth's parents sold their stately home in Andover, Massachusetts, and moved to Iowa when they learned of their daughter's desperate condition. Beth died in 1971, shortly after her youngest child graduated from high school. Despite the presence of three maternal figures - a mother, grandmother, and caregiver-Beth's daughter, Ann, experienced complex feelings of abandonment. She once saw her mother cry in quiet conversation with a clergyman, but never heard her mother complain. Photograph courtesy of Ann Brown LeMaster (who now resides in Dallas County).

Iowa, has been a collaborative effort between the State Library of Iowa and the State Historical Society of Iowa to document and preserve the history of polio in Iowa. The collection includes oral history interviews with physicians, pediatricians, registered nurses, and licensed practical nurses who worked with polio patients. Most important, the collection includes the voices of the people who were most affected by polio. Through their own words, they reveal how they felt, how they coped, 
how their communities responded, and how they survived the anguish of the "dreaded" disease. The taped interviews, transcripts, and associated materials are accessible in Special Collections at the State Historical Society of Iowa, Iowa City. In addition, 59 Iowans electronically submitted written narratives of their memories of how polio affected their lives, families, and communities to the Iowa Polio Stories Web site. ${ }^{5}$ The written narratives are a treasure trove of primary source material.

The Iowa Polio Stories Oral History Collection consists of 51 recorded audio interviews from Iowans scattered across 26 counties. ${ }^{6}$ The subjects, both men and women, ranged in age from 55 to 96 years old. The interviews are recorded primarily on cassette tapes; four are in digital format. Most interviews last approximately 45 to 60 minutes. Several interviews were recorded via telephone in order to ensure broad geographic scope across the state. Summaries are available online at the Iowa Center for the Book's Web site, as is an extensive bibliography of articles related to polio from twentieth-century periodicals, medical journals, and annual and biennial reports from the Iowa State Department of Health. Statistical accounts from the Iowa Department of Health and the medical profession are critical, but they do not necessarily capture the whole story. ${ }^{7}$

To facilitate accessibility and to aid researchers, all but one of the oral history recordings have been transcribed. The transcripts are filed along with the individual's biographical data form and oral history release form. Many interviewees' files also contain photographs, personal letters, news clippings, scrapbooks, medical letters, and documents generously shared from the personal collections of the interviewees.

This collection sought to capture the voices of three primary groups affected by polio: 1) the medical community; 2) family and friends of those afflicted; and 3) polio survivors. By capturing their voices, this project has made it possible to begin to document and preserve perhaps the most critical, yet overlooked element in the historical record: the personal experience.

5. www.iowacenterforthebook.org/ips-home.

6. Forty-nine participants submitted oral history release forms.

7. www.iowacenterforthebook.org/air/previous-years/ohs/ohcol/; www.iowacenterforthebook.org/air/previous-years/air07/Polio-in-Iowa. 
With only two interviews in the collection from African Americans - one physician and one polio survivor - the collection is not entirely comprehensive in scope. More must be done to capture the voices of diverse racial and ethnic immigrant Iowans and to document the efforts made by African American health professionals to overturn the idea of polio as a white disease. ${ }^{8}$ Through personal donations, however, the project did acquire photographs of African American women working as physical therapists at Broadlawn Medical Center and Blank Memorial Children's Hospital in Des Moines. Through the oral histories, we also know that a team of African American women worked in the basement of the Sister Kenny Institute in Minneapolis preparing hot packs during the early fifties. "Packers," as they were commonly called, worked in extremely uncomfortable conditions; they tolerated nauseating heat and the unpleasant smell of the wet wool used for therapy to treat polio victims.

The topic of polio fits into a number of important conceptual frameworks for scholars, historians, and educators. Like race, class, gender, and sexuality, disability studies is burgeoning as an analytic category of scholarship. University of Iowa historian Douglas Baynton has observed, "The polio epidemics that swept the country in the twentieth century had profound effects not only on the thousands of individuals and families but on the very culture of the area. One of the most significant, perhaps, was the advent of the disability rights movement, which drew much of its early leadership from the ranks of polio survivors." Baynton and others have reminded us that American society has come a long way from the rampant and institutionalized discrimination of the turn of the century. Like the Civil Rights Act, the 1990 Americans with Disabilities Act (ADA) has been interpreted as a critical landmark of civil rights legislation prohibiting discrimination. ${ }^{9}$ Yet the voices in this collection

8. Rogers, "Race and the Politics of Polio," 784.

9. Douglas C. Baynton, e-mail message to author, 9/9/2008 (quotation); idem, "Disability in History," Perspectives 44, no. 8 (2006), 5-7; idem, "Defectives in the Land: Disability and American Immigration Policy, 1882-1924," Journal of American Ethnic History 24 (2005), 31-44; idem, "Disability History: No Longer Hidden," Reviews in American History 32 (2004), 282-92; Paul K. Longmore and Laura Umansky, eds., The New Disability History: American Perspectives (New York, 2001). 


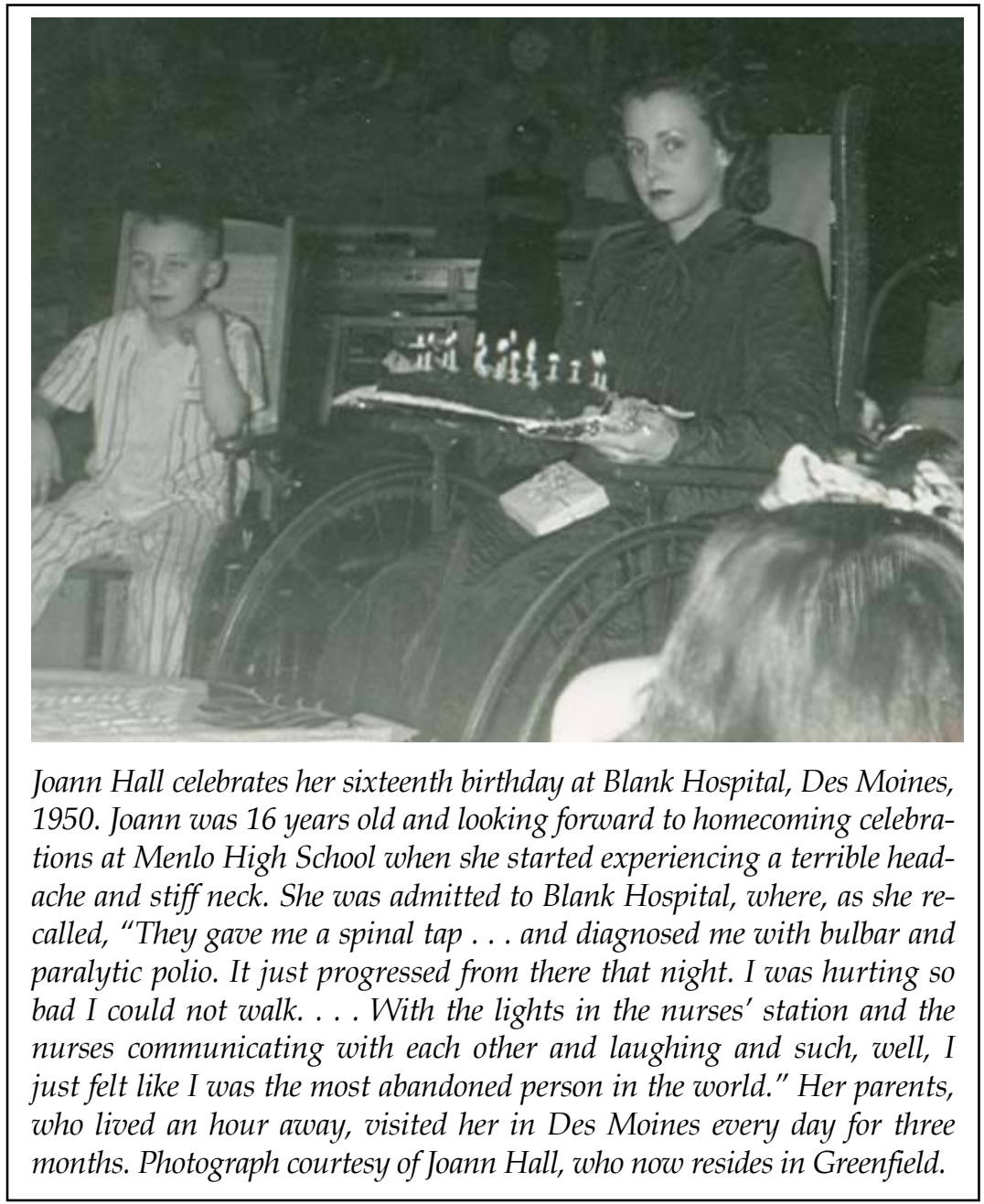

reveal that we still have a long way to go in this regard. Many interviewees reflected on the extent to which the law, despite good intentions, is not being enforced with enough tenacity or vigilance. Issues of mobility and accessibility remain a constant and recurring theme.

Disability, as a social and cultural construct, is an important lens to broader themes of accessibility, citizenship, and power for scholars of American history and culture. Yet the concept rarely surfaced as a metaphor in the rhetoric of polio survivors. 
Most of the Iowa polio survivors interviewed for this collection interpreted their "disability" as a source of inspiration, courage, and determination; and most offered commentary on the ways polio enhanced their compassion and empathy for others.

Many Americans born after the terror of the polio epidemics subsided remain oblivious to and unaware of the intensity of fear that swept the country or the overwhelming sense of desperation felt by families affected by polio. A serious problem currently exists for polio survivors who find that they need to educate their own physicians about the long-term effects of polio on their muscles, nerves, joints, and bones. This burden is exacerbated by a medical profession that has yet to officially acknowledge Post-Polio Syndrome in the nomenclature of medical diseases. According to Baynton, "The epidemics themselves have been well documented and their histories often told. What the Iowa Polio Stories Oral History Project will make possible are the histories of the subsequent lives of the polio survivors and how they were transformed by the disease." 10

The Iowa Polio Stories project is a valuable primary resource for all of these reasons. But it is also important to note that the project reflects a neat coincidence with its origins in the Iowa Center for the Book's All Iowa Reads program. A number of interviewees recalled how important reading was to their survival and recovery. Some mentioned in their oral histories the significance of libraries in their local communities. Others clearly remembered the way reading operated as a form of escapism. Patricia Moreland explained how reading gave her comfort and a sense of adventure when she was hospitalized as a seven-year-old at Blank Memorial Children's Hospital. "I loved to read. I would read three or four books a week in addition to my schoolwork. Part of the appeal of reading was that I could go into a whole other world - a world where I could run and jump and do things. I think that was partly why I loved to read so much. I still love to read." Reading enhanced imaginations and allowed survivors to break free of doctors, nurses, braces, and crutches - free of polio.

10. Baynton, e-mail. 